\title{
Feasibility of profound hypothermia as part of extracorporeal life support in a pig model
}

Christoph Weiser, MD, ${ }^{\mathrm{a}}$ Wolfgang Weihs, DVM, ${ }^{\mathrm{a}}$ Michael Holzer, MD, ${ }^{\mathrm{a}}$ Christoph Testori, MD, Anne-Margarethe Kramer, DVM, ${ }^{b}$ Christoph Kment, DI, ${ }^{\mathrm{c}}$ Martin Stoiber, DI, ${ }^{\mathrm{d}}$ Michael Poppe, ${ }^{\mathrm{a}}$ Christian Wallmüller, MD, ${ }^{\mathrm{a}}$ Peter Stratil, MD, ${ }^{\mathrm{a}}$ Michael Hoschitz, DSc, ${ }^{\mathrm{e}}$ Anton Laggner, MD, ${ }^{\mathrm{a}}$ and Fritz Sterz, MD

\section{ABSTRACT}

Objective: To investigate the feasibility of a refined aortic flush catheter and pump system to induce emergency preservation and resuscitation before extracorporeal cardiopulmonary resuscitation in a normovolemic cardiac arrest swine model simulating near real size/weight conditions of adults.

Methods: In this feasibility study, 8 female Large White breed pigs weighing 70 to $80 \mathrm{~kg}$ underwent ventricular fibrillation cardiac arrest for 15 minutes, followed by $4^{\circ} \mathrm{C}$ aortic flush $(150 \mathrm{~mL} / \mathrm{kg}$ for the brain; $50 \mathrm{~mL} / \mathrm{kg}$ for the spine) via a new hardware ensued by resuscitation with extracorporeal cardiopulmonary resuscitation.

Results: Brain temperature was lowered from $39.9^{\circ} \mathrm{C}$ (interquartile range [IQR] 39.6-40.3) to $24.0^{\circ} \mathrm{C}$ (IQR 20.8-28.9) in 12 minutes (IQR 11-16) with a median cooling rate of $1.3^{\circ} \mathrm{C}$ (IQR 0.7-1.6) per minute. A median of $776 \mathrm{~mL}$ (IQR 673-840) per minute with a median pump pressure of $1487 \mathrm{~mm} \mathrm{Hg}$ (IQR 1324-1545) were pumped to the brain.

Conclusions: With the new hardware, we were able to cool the brain within a few minutes in a large pig cardiac arrest model. The exact position; the design, diameter, and length of the flush catheter; and the brain perfusion pressure seem to be critical to effectively reduce brain temperature. Redistribution of peripheral blood could lead to sterile inflammation again and might be avoided. (J Thorac Cardiovasc Surg 2017;154:867-74)

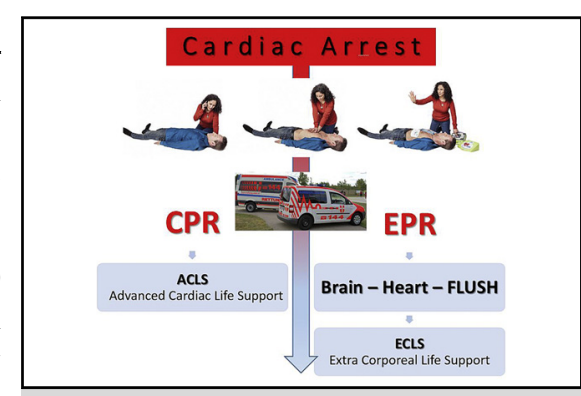

Future chain of survival with emergency preservation and resuscitation (EPR).

\section{Central Message}

One step further toward emergency preservation and resuscitation with a refined aortic flush catheter and pump system showing that it is still worthwhile to go the long pathway to daily clinical use.

\section{Perspective}

The developed emergency preservation and resuscitation hardware demonstrated its feasibility in near real size/weight conditions of adults. We were able to cool the brain within a few minutes. The information about the exact position, design, diameter, length of the flush catheter, and the brain perfusion pressure gained will serve as a valuable source for refining the flush hardware.

See Editorial Commentary page 875 .
Although there have been advances in the treatment of patients with cardiac arrest (CA) in the past decades, survival and good neurologic recovery after CA is still a rare event. ${ }^{1}$ There is growing evidence that extracorporeal

From the Departments of ${ }^{\mathrm{a}}$ Emergency Medicine and ${ }^{\mathrm{b}}$ Biomedical Research, ${ }^{\mathrm{e}}$ Technology Transfer Office, and ${ }^{\mathrm{d} C e n t e r}$ for Medical Physics and Biomedical Engineering, Medical University of Vienna, Vienna; and ${ }^{\mathrm{c}}$ Austrian Center for Medical Innovation and Technology, Wiener Neustadt, Austria.

This study was funded by the AWS-P1308407 fund (Austria Wirtschaftsservice). The study sponsors had no influence on the study design; on the collection, analysis, and interpretation of data; in the writing of the manuscript; and in the decision to submit the manuscript for publication. International patent application pending.

Received for publication Sept 1, 2016; revisions received Feb 2, 2017; accepted for publication March 4, 2017; available ahead of print April 19, 2017. cardiopulmonary resuscitation (ECPR) could be a promising tool for surviving out-of-hospital $(\mathrm{OOH}) \mathrm{CA}$ if an experienced team is readily available (Figure 1). ${ }^{2-6}$ At the moment, only a few patients have the chance to benefit

Address for reprints: Fritz Sterz, MD, Universitätsklinik für Notfallmedizin am Allgemeinen Krankenhaus der Stadt Wien, Medizinische Universität Wien, Währinger Gürtel 18-20/6D, 1090 Wien, Austria (E-mail: fritz.sterz@ meduniwien.ac.at). 0022-5223

Copyright @ 2017 by The American Association for Thoracic Surgery. This is an open access article under the CC BY-NC-ND license (http://creativecommons.org/ licenses/by-nc-nd/4.0/).

http://dx.doi.org/10.1016/j.jtcvs.2017.03.055 


\section{Abbreviations and Acronyms \\ $\mathrm{AFBC}=$ aortic flush balloon catheter \\ $\mathrm{CA}=$ cardiac arrest \\ ECG = electrocardiogram \\ ECLS $=$ extracorporeal life support \\ ECPR = extracorporeal cardiopulmonary resuscitation \\ EPR $=$ Emergency Preservation and Resuscitation \\ IQR = interquartile range \\ OOHCA $=$ out-of-hospital cardiac arrest \\ PEEP = positive end-expiratory pressure \\ ROSC = restoration of spontaneous circulation \\ $\mathrm{VF}=$ ventricular fibrillation}

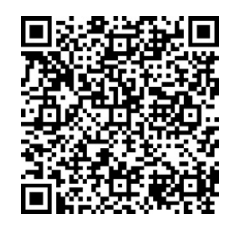

from ECPR. ${ }^{2,7}$ The concept of emergency preservation and resuscitation (EPR) aims to increase the number of potential patients benefiting from ECPR. ${ }^{8-10}$ In 1990, a study on therapeutic deep hypothermic circulatory arrest showed that 60 to 90 minutes of circulatory arrest can be survived with good neurologic recovery. ${ }^{11}$ In 1999 , a cold flush applied by a catheter in the aortic arch could successfully resuscitate dogs after exsanguination $\mathrm{CA}$ up to a no-flow time of 120 minutes with good neurologic outcome. ${ }^{12} \mathrm{Be}-$ tween 2006 and 2012 in a series of experiments, EPR and ECPR has shown after ventricular fibrillation (VF) CA up to a no-flow time of 13 minutes to be superior to conventional resuscitation and ECPR alone. ${ }^{13-17}$ There is currently a human clinical trial of aortic flush under way (https://clinicaltrials.gov/ct2/show/NCT01042015).

Therefore, the necessity existed to further develop the EPR hardware. The aim of this study was to investigate in near real size/weight conditions of adults the feasibility and performance of a newly developed and refined flush hardware (Video 1).

\section{METHODS}

The experiments were approved by the animal investigation committee (Ethik-Kommission der Medizinischen Universität Wien zur Beratung und Begutachtung von Forschungsprojekten am Tier; 1488/155-1997/98; 2014/15) and performed by qualified personnel and supervised by veterinarians. ${ }^{18}$ In this feasibility trial, 8 female Large White breed pigs weighing 70 to $80 \mathrm{~kg}$ were brought to the laboratory stable 7 days before the experiment. After 15 minutes of VFCA, the brain was cooled as low as possible with a flush solution injected via a newly developed flush

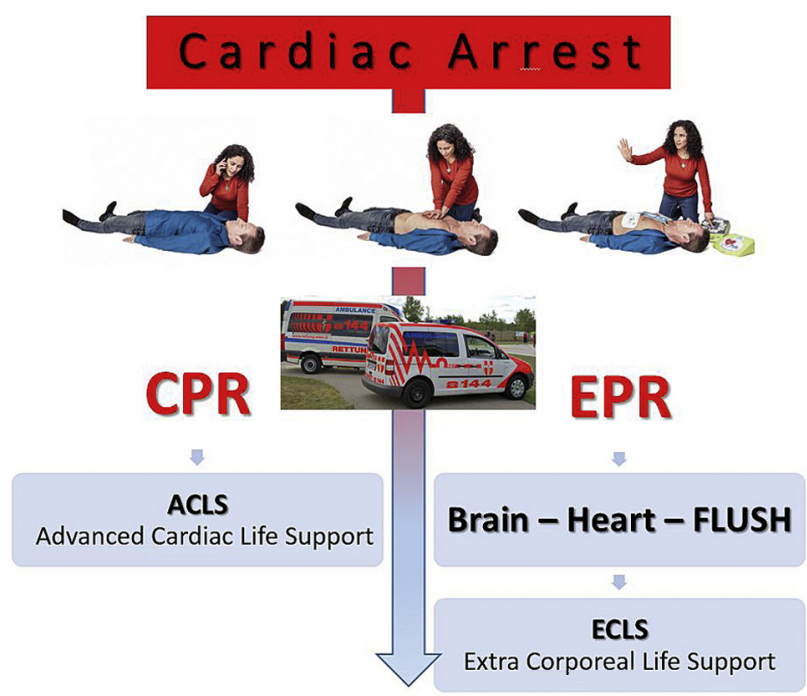

FIGURE 1. Future chain of survival with emergency preservation and resuscitation $(E P R)$.

pump and an aortic flush balloon catheter (AFBC) followed by ECPR. The primary goal of this feasibility study was the achievable brain-cooling rate and attainable minimal brain temperature (not fixing a target temperature), and measurement of flow and pressure regarding to the AFBC and the Flush pump.

\section{Aortic Flush Balloon Catheter}

The AFBC (Bavaria Medical Technology, Wessling, Germany) is a 2-balloon 16-F catheter, $90 \mathrm{~cm}$ long with 5 separated lumina. Two lumina were used to inflate/deflate the balloons with $\mathrm{NaCl} 0.9 \%$, the other 3 lumina for applying the flush solution. The main lumen, for the brain flush, ended at the tip of the catheter. The other 2 lumina ended in 6 holes on both sides between the balloons to flush the arteries supplying the spinal cord. To

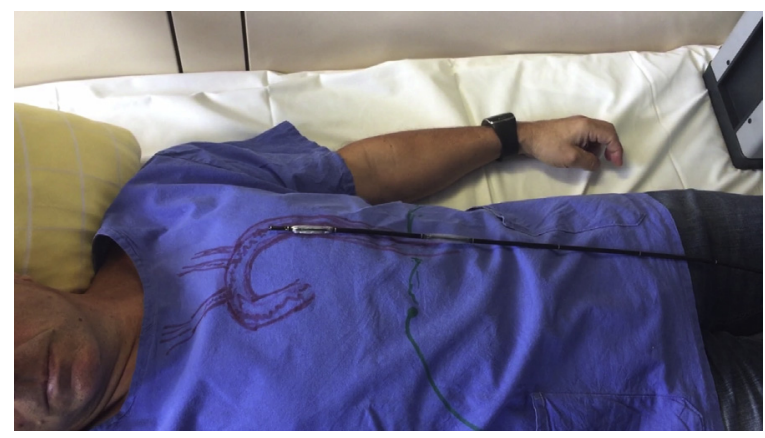

VIDEO 1. Drs Weiser and Sterz explain the setup to induce profound hypothermia in cardiac arrest as part of extracorporeal life support (ECLS). The aortic catheter is inserted via the femoral artery and advanced into the descending thoracic aorta. The tip lies in the distal arch with a balloon in the proximal descending aorta to isolate the cerebral circulation. There is also a second balloon that sits in the distal descending aorta. Additional infusion ports between the 2 balloons rapidly infuse cold saline to cool the spinal cord. After completion of the predetermined cerebral and spinal flush infusion, the balloons were deflated, the catheter was removed, and ECLS was initiated. Video available at: http://www.jtcvsonline.org/ article/S0022-5223(17)30565-2/addons. 
TABLE 1. Blood laboratory results

\begin{tabular}{|c|c|c|c|c|c|c|}
\hline & $\begin{array}{c}\text { Baseline } \\
\text { (before preparation) }\end{array}$ & $\begin{array}{c}\text { Baseline } \\
\text { (after preparation) }\end{array}$ & $\begin{array}{c}\text { Cardiac arrest } \\
(+13 \mathrm{~min})\end{array}$ & ECLS (start) & $\operatorname{ECLS}(+12 \min )$ & $\operatorname{ECLS}(+\mathbf{3 0} \mathbf{~ m i n})$ \\
\hline $\mathrm{pH}$ & 7.45 (7.41-1.47) & $7.5(7.49-7.51)$ & $7.24(7.15-7.27)$ & $6.6(6.49-6.89)$ & $6.93(6.85-7.23)$ & $6.89(6.85-7.08)$ \\
\hline $\mathrm{pCO} 2, \mathrm{~mm} \mathrm{Hg}$ & $39(37-42)$ & $35(25-39)$ & $62(57-69)$ & $28(14-29)$ & $58(29-69)$ & $48(38-69)$ \\
\hline $\mathrm{pO} 2, \mathrm{~mm} \mathrm{Hg}$ & $146(130-171)$ & $132(121-140)$ & $32(21-34)$ & $110(63-196)$ & $78(74-135)$ & $89(84-103)$ \\
\hline Hemoglobin, g/dL & $8.8(8.8-9.1)$ & $8.3(8.0-8.5)$ & $4(2.9-6.8)$ & $0.13(0.1-0.4)$ & $5.3(4.5-6.1)$ & $5.5(5-7.2)$ \\
\hline Potassium, mmol/L & $3.6(3.5-3.9)$ & $4.3(4.2-4.7)$ & $4.3(3.5-4.6)$ & $1.1(1.0-2.1)$ & $4.2(4.0-4.4)$ & $3.8(3.5-3.8)$ \\
\hline Glucose, mg/dL & $90(85-103)$ & $105(99-114)$ & $76(57-97)$ & $70(35-92)$ & $216(138-269)$ & $170(141-236)$ \\
\hline Lactate, $\mathrm{mmol} / \mathrm{L}$ & $3.2(2.7-3.5)$ & $1.6(1.4-1.9)$ & $4.0(2.8-4.9)$ & $0.9(0.2-1.5)$ & $10.5(6.2-11.9)$ & $8.4(6.7-12.1)$ \\
\hline
\end{tabular}

Data are presented as median (interquartile range). ECLS, Extracorporeal life support.

guarantee these 2 separated streams, 2 balloons were necessary: one to occlude the aorta distal to the brain outflow and a second to prevent the flush solution from trickling away into visceral and distal vessels. The first balloon was located near the tip of the catheter with a length of $2 \mathrm{~cm}$ and the second balloon within $20 \mathrm{~cm}$ distal from the first balloon with a length of $4 \mathrm{~cm}$. The balloons were designed to stabilize the catheter and to fully occlude the aorta during the flush procedure. Preliminary in vitro tests were undertaken to prove the catheters' stability and balloon occlusion with the maximum amounts of flush-fluids $(1000 \mathrm{~mL} / \mathrm{min}$ at the tip [brain] and $500 \mathrm{~mL} / \mathrm{min}$ at the side holes [spine]) administered.

\section{Flush Pump}

To administer these amounts of fluids in a short time, we developed a pump that allowed us to have control over and monitor data on applied pressure and volume. The flush pump had 2 separate units: each unit consisted of a roller pump, with its own controller to regulate the speed of the pump, a mechanical pressure measure unit, an ultrasound-guided flow measurement, and a temperature measurement unit.

\section{Animal Preparation}

The animals were fasted 12 hours before the experiment with free access to water. After premedication in the stable with ketamine $(25 \mathrm{mg} / \mathrm{kg})$ and acepromazine $(1.75 \mathrm{mg} / \mathrm{kg})$, anesthesia was induced in the operating theater with a bolus of propofol $2 \%(10 \mathrm{~mL})$, fentanyl $(0.2 \mathrm{mg})$, and rocuronium $(20 \mathrm{mg})$. Animals were intubated with a conventional endotracheal tube and mechanically ventilated (Servo 300; Maquet Critical Care, Solna, Sweden) with tidal volumes of $10 \mathrm{~mL} / \mathrm{kg}$, positive end-expiratory pressure (PEEP) of $5 \mathrm{~cm} \mathrm{H}_{2} \mathrm{O}, \mathrm{FIO}_{2}$ of 0.3 , and a ratio of inspiration to expiration (I:E) of $1: 2$. The respiratory rate was adjusted to a $\mathrm{PaCO}_{2}$ of 35 to $40 \mathrm{~mm} \mathrm{Hg}$. During preparation, propofol $2 \%(20 \mathrm{mg} / \mathrm{kg} / \mathrm{h})$, fentanyl $(10 \mu \mathrm{g} / \mathrm{kg} / \mathrm{h})$, and rocuronium $(2 \mathrm{mg} / \mathrm{kg} / \mathrm{h})$ were given.

Electrocardiogram (ECG) electrodes and a pulse-oximeter probe were attached; arterial catheters (brachial artery left and right) and a pulmonary artery catheter were placed. Temperature probes (Neurodur-Temp; Raumedic, Helmbrechts, Germany) were inserted into the right and left frontal brain lobes $(1 \mathrm{~cm}$ right and left of the sagittal suture and $1 \mathrm{~cm}$ in front of the coronal suture) via boreholes to a depth of $2.5 \mathrm{~cm}$ (animals 1 to 4 had only the left-brain temperature probe). Additional temperature probes were inserted through the brachial arteries on both sides (animals 5-8) and in the esophagus and bladder for $39.0^{\circ} \mathrm{C} \pm 0.2^{\circ} \mathrm{C}$ baseline levels.

The AFBC was inserted into the left femoral artery via cut-down and advanced into the thoracic aorta until the tip of the catheter was placed right at the beginning of the descending aorta (correct position confirmed via radiograph). A venous bypass cannula ( $23 \mathrm{~F}$ ) and arterial bypass cannula (14F) (BioMedicus; Medtronic, Inc., Minneapolis, Minn) were inserted into the right femoral vein (advanced into the right atrium) and into the right femoral artery.

\section{Cardiac Arrest}

After cardiopulmonary parameters stabilized and baseline measurements, heating devices, intravenous (IV) fluids, and anesthesia were discontinued, heparin (50 IU/kg IV) was given to avoid tube clotting during CA. Two needle electrodes were placed into the pectoral muscles for induction of VFCA via an external current impulse of $90 \mathrm{~V}$ and $60 \mathrm{~Hz}$ of 2seconds' duration. Drop of blood pressure and ECG readings confirmed CA.

\section{Flush Solution}

At 14 minutes of VFCA, the brain lumen of the AFBC was primed with $\mathrm{NaCl} 0.9 \% 50 \mathrm{~mL}$ containing epinephrine $0.04 \mathrm{mg} / \mathrm{kg}$ and vasopressin $0.6 \mathrm{IU} / \mathrm{kg}$. At 15 minutes of VFCA, a $4{ }^{\circ} \mathrm{C}$ flush solution was administered via the AFBC (brain: $\mathrm{NaCl} \quad 0.9 \% \quad 150 \mathrm{~mL} / \mathrm{kg}$ with epinephrine $0.06 \mathrm{mg} / \mathrm{kg}$, vasopressin $0.9 \mathrm{IU} / \mathrm{kg}$ and heparin $37.5 \mathrm{IU} / \mathrm{kg}$; spine: $50 \mathrm{~mL} / \mathrm{kg} \mathrm{NaCl} 0.9 \%$ with epinephrine $0.02 \mathrm{mg} / \mathrm{kg}$, vasopressin $0.3 \mathrm{IU} / \mathrm{kg}$ and heparin $40 \mathrm{IU} / \mathrm{kg}$ ). The basis for choosing the perfusion compositions and rates were experiences from former experiments. ${ }^{13,16}$ During the flush procedure, the venous bypass cannula was opened to drain blood and fluids from the right heart $(150 \mathrm{~mL} / \mathrm{kg}){ }^{13}$ The first $1000 \mathrm{~mL}$ of drained blood was collected in citrate bags to be returned as blood transfusion during extracorporal life support (ECLS). After the entire flush volume was administered, the AFBCs were immediately deflated and the catheter was removed.

\section{Extracorporeal Cardiopulmonary Resuscitation}

Immediately after the flush, ECPR was started with a centrifugal pump (Bio-Pump; Medtronic, Inc.), a hollow-fiber oxygenator with a plasmaresistant fiber (Minimax-Plus; Medtronic, Inc), and a heater-cooler system (Heater-Cooler-System; Stoeckert Instruments, Munich, Germany). Target continuous flow rate was 60 to $100 \mathrm{~mL} / \mathrm{kg} / \mathrm{min}$ to keep mean arterial pressure $>65 \mathrm{~mm} \mathrm{Hg}$ and pigs were rewarmed to $33^{\circ} \mathrm{C}$. Ventilation was restarted with ECPR beginning with tidal volumes of $4 \mathrm{~mL} / \mathrm{kg}$, PEEP of $10 \mathrm{~cm} \mathrm{H}_{2} \mathrm{O}, \mathrm{FIO}_{2}$ of 0.4 , and an $\mathrm{I}: \mathrm{E}$ of 1:2. Oxygen and air flow were adjusted to achieve a $\mathrm{paCO}_{2}$ of 35 to $40 \mathrm{~mm} \mathrm{Hg}$ and a $\mathrm{paO}_{2}$ of 80 to $120 \mathrm{~mm} \mathrm{Hg}$. Even though restoration of spontaneous circulation (ROSC) was no study goal, we tried to achieve ROSC while a maximal ECPR duration of 60 minutes. If the rhythm was shockable, 3 shocks $\left(150 \mathrm{~J}\right.$ each) were applied when the esophageal temperature $\left(\mathrm{T}_{\mathrm{es}}\right)$ reached $28^{\circ} \mathrm{C}$. Every 2 minutes, 1 biphasic shock with $200 \mathrm{~J}$ was repeated if still shockable. Epinephrine $(0.04 \mathrm{mg} / \mathrm{kg})$ and vasopressin $(0.4 \mathrm{IU} / \mathrm{kg})$ were administered at the start of ECPR followed by epinephrine every 4 minutes and vasopressin every 8 minutes. If ROSC was achieved, the experiment was terminated with $7 \mathrm{~mL} / \mathrm{kg}$ propofol $2 \%$ and $40 \mathrm{mmol}$ potassium.

\section{Additional Measurements}

To gather further information on local flow and catheter position, contrast agencies (Iomeron iodine $400 \mathrm{mg} / \mathrm{mL}$ ) with $\mathrm{NaCl} 0.9 \% 500 \mathrm{~mL}$ was given via the distal lumen of the AFBC during the 15 minutes of CA. Flush volume distribution was imaged with digital subtraction angiography.

Behavior of the aortic valve, the ascending aorta, and the left ventricle during the flush procedure at the onset of heart muscle contractions during ECPR was observed with transesophageal echocardiography. 


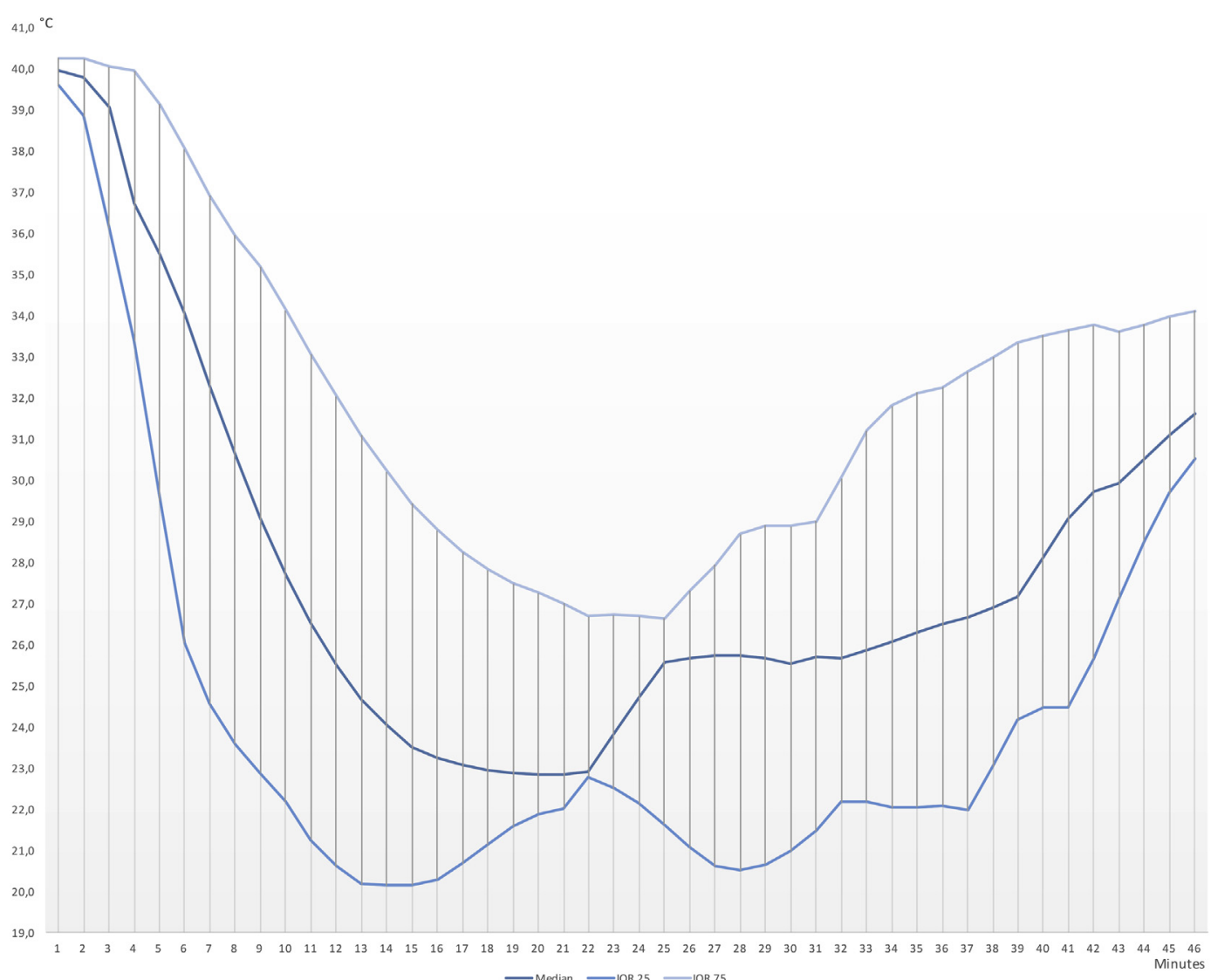

FIGURE 2. Brain temperature during flush and bypass.

\section{RESULTS}

In this VFCA model, 8 pigs with a median weight of $73 \mathrm{~kg}$ (interquartile range [IQR] 72.0-76.5) received $150 \mathrm{~mL} / \mathrm{kg}$ flush within 12 minutes (IQR 11-16) and ECPR was started 27 minutes (IQR 26-31) after CA (Table 1).

\section{Temperature}

Brain temperature $\left(\mathrm{T}_{\mathrm{br}}\right)$ was lowered from $39.9^{\circ} \mathrm{C}$ (IQR 39.6-40.3) to $24.0^{\circ} \mathrm{C}$ (IQR 20.8-28.9) with a median cooling rate of $1.3^{\circ} \mathrm{C} / \mathrm{min}$ (IQR $0.7-1.6$ ). During ECPR. the median
$\mathrm{T}_{\text {br }}$ was $25.9^{\circ} \mathrm{C}$ (IQR 20.2-33.4) and returned to $33.0^{\circ} \mathrm{C}$ within 31 minutes (IQR 24-37) (Figure 2).

\section{Hemoglobin Fall and Rise}

Because of venting the right heart, the central measured (pulmonary artery) hemoglobin at the end of the flush procedure was nearly zero. During the flush, a lot of blood pooled in the peripheral veins and arteries, which we were not able to flush out with the AFBC (Figure 3). This and the first liter of saved venting blood, which was retransfused, was the reason for the hemoglobin rise over time during concomitant ECPR.

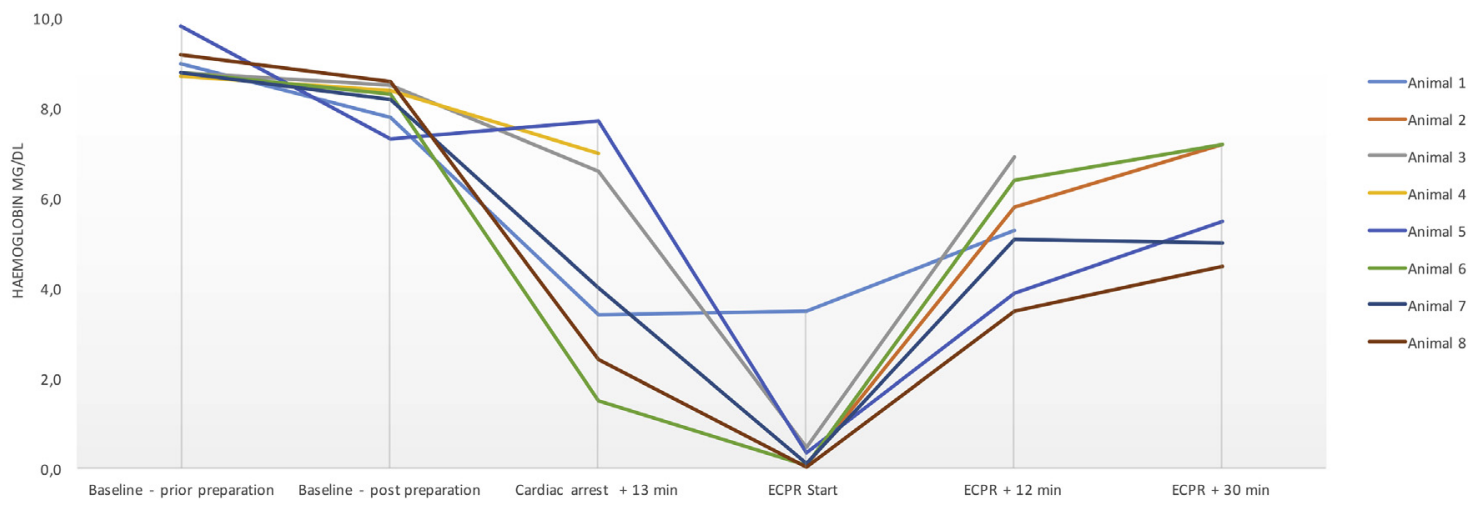

FIGURE 3. Fall and rise of hemoglobin during flush and bypass. ECPR, Extracorporeal cardiopulmonary resuscitation. 
TABLE 2. Flush procedure data

Animal weight, $\mathrm{kg}$

Flush duration, min

Bypass start after cardiac arrest, min

Bran temperature delta, ${ }^{\circ} \mathrm{C} / \mathrm{min}$

Vented venous volume, $\mathrm{mL}$

Brain flush volume, $\mathrm{mL}$

Spine flush volume, $\mathrm{mL}$

Brain perfusion pump pressure, $\mathrm{mm} \mathrm{Hg}$

Spine perfusion pump pressure, $\mathrm{mm} \mathrm{Hg}$

Data are presented as median (interquartile range).

\section{Flush Volumes}

As presented in Table 2, the median flush volumes for the brain were 10,907 mL (IQR 8911-12,390) and for the spine were $4912 \mathrm{~mL}$ (IQR 4813-5106). The vented volume during flush was $10,950 \mathrm{~mL}$ (IQR 10,800-11,475). Overall, the procedure caused $+5867 \mathrm{~mL}$ (IQR 3924-7021) of additional intracorporeal fluids.

\section{Flush Pump}

A median of $776 \mathrm{~mL} / \mathrm{min}$ (IQR 673-840) was pumped to the brain with a median pump pressure of $1487 \mathrm{~mm} \mathrm{Hg}$ (IQR 1324-1545) to reach a median subclavian artery pressure of $52 \mathrm{~mm} \mathrm{Hg}$ (IQR 42-67) (Figure 4).

\section{Transesophageal Echocardiography and Observed ROSC}

Before $\mathrm{CA}$, as well as during the experiment, none of the animals had aortic valve insufficiency. Even though ROSC was no study goal, during ECPR when $\mathrm{T}_{\text {br }}$ came back to $28^{\circ} \mathrm{C}$, we observed that the right heart started to beat again, with acceptable pressures and stroke volumes measured via the pulmonary artery catheter. At the same time, the left ventricle started to fibrillate. Sustained ROSC could be achieved in 2 animals (25\%); the remaining animals stayed in VF.

\section{DISCUSSION}

In this feasibility study, a new unique novel multilumen catheter and perfusion apparatus were used to rapidly induce profound cerebral hypothermia for potential preservation of the brain and heart after $\mathrm{CA}$ with a no-flow time of 15 minutes in human-sized animals. We could show that the developed hardware was able to cool the brain within a few minutes. The experiments described provide initial data on how effectively this approach can cool the brain in a CA state. The main findings of our study are the necessity of the exact intra-aortic AFBC placement, a missing relationship between generated aortic pressure and cooling effectiveness, and a substantial auto

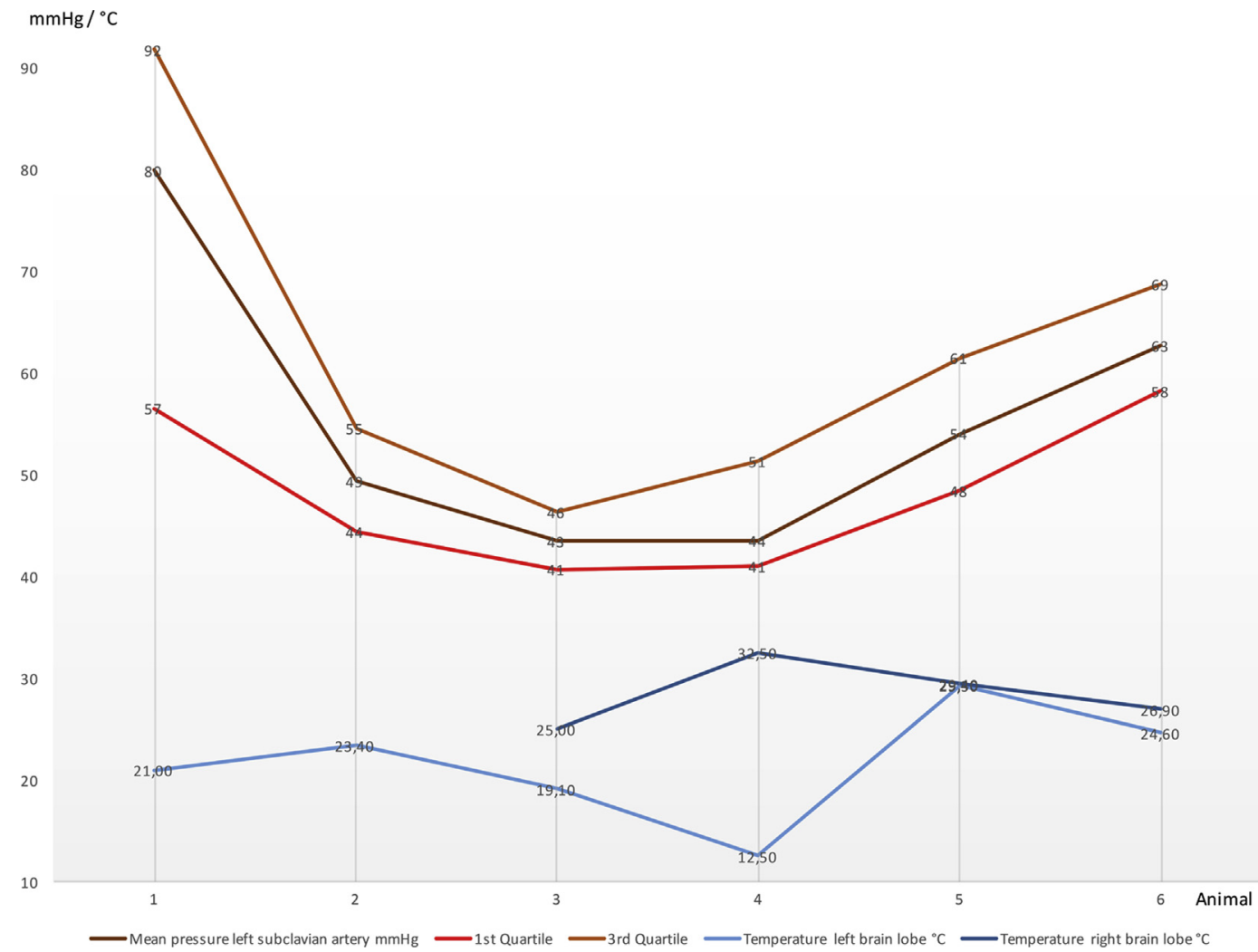

FIGURE 4. Lowest brain temperature versus cumulated left subclavian artery pressure during flush procedure. 
redistribution of the hemoglobin levels despite high flush volumes. Furthermore, during rewarming and VF of the left ventricle, we found a return of spontaneous contractions in the right heart with increasing temperatures.

\section{Cooling Speed}

Janata and colleagues ${ }^{13}$ achieved a median cooling rate of $4.7^{\circ} \mathrm{C} / \mathrm{min}$ by using the same procedure but with a different cooling catheter and pump. Even the best cooling rate of our study with $3.2^{\circ} \mathrm{C} / \mathrm{min}$ did not accomplish their median rate. This might be explained by some differences between the trials: Janata and colleagues ${ }^{13}$ used small 31- to 42-kg pigs, and a 14-F single lumen catheter oriented to the brain. They used $100 \mathrm{~mL} / \mathrm{kg}$ of the $\mathrm{NaCl} 0.9 \%$ plus vasopressin flush solution in their phase II model. No-flow time was 10 minutes in comparison to our 15-minute model. Their flush time on average was 180 seconds; our setup had a median flush time of 720 seconds. Therefore, Janata and colleagues ${ }^{13}$ had a better brain-cooling rate in a shorter time. We suppose the main difference between the studies is the animal size/weight. As presented in Figure 4, we could not find a relationship between measured pressure in the subclavian artery and cooling effectiveness in the brain. This suggests a nonlinear relationship between aortic pressure and brain blood flow, with a plateau at higher pressures. Unfortunately, we are not able to report about the cooling effect on the spinal cord because of technical problems in placing temperature probes.

There are 2 possibilities to solve this problem. First, more powerful pumps might reach the same flow rates during the EPR procedure. Janata and colleagues ${ }^{13,14}$ and Weihs and colleagues $^{19}$ reported approximately $1.2 \mathrm{~L} / \mathrm{min}$ in their trials differing from our measured median brain flush of $776 \mathrm{~mL} / \mathrm{min}: 35 \%$ less volume per minute. Even though we used a $16-\mathrm{F}(5.33-\mathrm{mm})$ catheter (5 lumina) instead of a 14-F catheter (single lumen) by Janata and colleagues ${ }^{13,14}$ and Weihs and colleagues,${ }^{19}$ our brain flush lumen had just as effective diameter of $7.8 \mathrm{~F}(2.6 \mathrm{~mm})$. Other studies did not report information on the inside diameter. $^{11,13,15,16,20-23}$ Following the Hagen-Poiseuille equation, the diameter of the catheter is most important for the transported fluid over time. This means that a diameter reduction of $10 \%$ leads to a flow reduction of $34 \%$, which can be compensated by $52 \%$ more pressure difference. But the assumptions for the Hagen-Poiseuille equation are that the fluid is incompressible and the flow is laminar. These are the limitations of the equation in our setting: blood is not Newtonian and we do not know if the flow in the catheter was laminar or turbulent. As the flow rates through the catheter increase, it is more likely to generate turbulent flow, which increases flow resistance.

One additional factor could be the material of the catheters used. Because of the experience of unstable bending

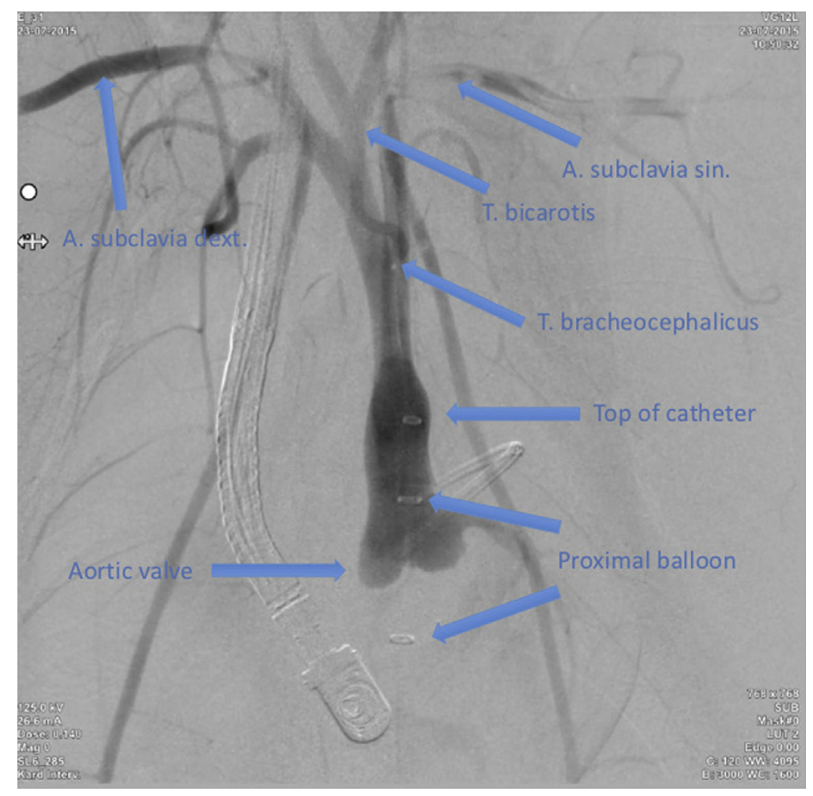

FIGURE 5. Labeled digital subtraction angiography during flush of the brain (the tip of the catheter in this picture is slightly too high: in the descending part of the aortic root).

catheters in former experiments of our group, we decided to use a catheter material that is as stiff as possible to be still introduced into the femoral artery and to be moved forward into its final position. By contrast, the Foley catheter, which was used in some studies, is a flexible tube. ${ }^{13,14,16} \mathrm{We}$ hypothesize that this flexible tube is not able to stay in an exact position, but has the possibility to expand in diameter if fluids are pumped with high pressure through the catheter. However, as the vascular access is the limitation, larger catheter diameters are limited.

\section{Volume Overload}

After the flush application was finished, there was a median additional intracorporeal volume of $5687 \mathrm{~mL}$. This applies to our clinical experience with ECPR patients who need a large amount of additional volume during the first hours on bypass. ${ }^{24}$ This is caused by a volume demand of the extracorporeal bypass circuit and second by the capillary leakage caused by a sterile inflammatory sepsislike response. ${ }^{25}$ Therefore, we do not consider the $6 \%$ to $7 \%$ additional volume per body weight as harmful during this initial time on bypass. However, we are convinced that this additional volume must be removed as soon as the patient is stabilized. ${ }^{26}$ In our earlier studies, we showed that there was superiority in neurologic outcome by using this technique with a high-volume flush comparing conventional cardiopulmonary resuscitation (CPR)/ECLS. ${ }^{14}$ These volume overloads would not be necessary if we could cool down blood during the extracorporeal ECLS circuit to $4^{\circ} \mathrm{C}$, but by now we are technically 
not able to solve this condition. More studies are necessary to design the perfect reperfusion fluid. This reperfusion fluid should be a cocktail that refers for reduction of the response inflammatory syndrome and cooling of the tissue. There is need to further discuss this important limitation in our strategy creating an ideal resuscitation fluid, but this would be the topic of a different project and extends the bounds of this article.

\section{Precise Catheter Placement}

The necessity for the precise catheter placement below the separation of the truncus brachiocephalicus in the aorta (Figure 5) has never before been reported and seems to be critical for effective cooling of the brain. Although we positioned the catheter under radiographic control, we experienced substantial differences in $\mathrm{T}_{\mathrm{br}}$ curves, indicating large influences by small and nondetectable differences of position of the catheter in relation to the truncus brachiocephalicus. To overcome this problem, we used multilumen central venous catheters with a length of $8 \mathrm{~cm}$ (Arrow International, Reading, $\mathrm{Pa}$ ) to measure arterial pressures in both brachial arteries and to introduce very small temperature probes on both sides. This, however, did not substantially improve cerebral cooling effectivity. It might be necessary to introduce the flush catheter directly into the truncus bicaroticus to achieve maximum effectivity. But this approach could then not be directly transferred to the different human aortic anatomy. In the human clinical setting, or even preclinical setting, ultrasound can deliver the necessary information, with an epigastric view on the upper abdominal aorta where the catheter and the placement of the lower balloons can be identified. ${ }^{27-29}$

\section{ROSC of the Right Heart}

During the flush and ECPR procedure, we observed with continuous transesophageal echo isolated ROSC of the right heart while the left heart was still fibrillating. One explanation might be that reperfusion of the smaller right ventricle muscle might be initially better than of the larger left ventricle. Echo also has proven the aortic valve during the EPR procedure being closed and tight. Distension of the left ventricle can be a problem in prolonged CA and resuscitation efforts. Maybe the use of an Impella or intra-aortic balloon pump device could help to overcome this problem by left ventricular unloading. ${ }^{30,31}$

\section{Additional Limitations}

The bore holes for the $\mathrm{T}_{\mathrm{br}}$ probes were exactly positioned as planned, but the intracerebral placement of the probes was done blind. We did placement control by radiograph, but we cannot distinguish if the probe was placed near a brain artery or not. This could partly explain the difference between temperatures monitored as presented in Figure 2. Because of technical problems with data monitoring of subclavian artery pressures in 2 experiments, we can present subclavian artery pressure data of only 6 animals. Furthermore, we had technical problems with the blood gas device on animal 4. As ROSC was no study goal, we did not use the whole 60 minutes of ECPR in all animals, but because of the interesting observations of right heart ROSC, we reported these results. The "missing relationship between generated aortic pressure and cooling effectiveness" is not completely clear from this small set of experiments, but it raises important questions about the relationship among blood pressure, vascular resistance, and actual perfusion when using an invasive perfusion technique for resuscitation. In addition, it was not the goal to conduct sophisticated investigations of organ injury, postmortem procedures, and outcome, such as the comparison with the standard CPR control group.

\section{CONCLUSIONS}

With the new AFBC and flush pump for EPR, we were able to cool the brain within a few minutes in a large pig CA model. The catheter performed as desired; however, the exact position; the design, diameter, and length of the flush catheter; and the brain perfusion pressure seems still to be critical to effectively reduce $\mathrm{T}_{\mathrm{br}}$ and, therefore, will have no impact on daily clinical practice jet. Additionally, the redistribution of peripheral blood could lead to sterile inflammation again and might be avoided by the development of specific blocking flush-solutions. The next steps are designated to simplify the procedure even more, to reduce the technical effort, and to develop the optimal "flush cocktail" to improve effectiveness.

\section{Conflict of Interest Statement}

Authors have nothing to disclose with regard to commercial support.

The authors thank the team of the Vienna Resuscitation Group as the team of the Department for Biomedical Research for their support during the project.

\section{References}

1. Berdowski J, Berg RA, Tijssen JG, Koster RW. Global incidences of out-ofhospital cardiac arrest and survival rates: systematic review of 67 prospective studies. Resuscitation. 2010;81:1479-87.

2. Lazzeri C, Valente S, Peris A, Gensini GF. Extracorporeal life support for out-ofhospital cardiac arrest: part of a treatment bundle. Eur Heart J Acute Cardiovasc Care. 2016;5:512-21.

3. Poppe M, Weiser C, Holzer M, Sulzgruber P, Datler P, Keferböck M, et al. The incidence of "load\&go" out-of-hospital cardiac arrest candidates for emergency department utilization of emergency extracorporeal life support: a one-year review. Resuscitation. 2015;91:131-6.

4. Anselmi A, Flécher E, Corbineau H, Langanay T, Le Bouquin V, Bedossa M, et al. Survival and quality of life after extracorporeal life support for refractory cardiac arrest: a case series. J Thorac Cardiovasc Surg. 2015;150:947-54.

5. Singal RK, Arora RC. Use of extracorporeal membrane oxygenation in cardiac arrest: developing a new frontier. J Thorac Cardiovasc Surg. 2015;150: $1350-1$. 
6. Spangenberg T, Meincke F, Brooks S, Frerker C, Kreidel F, Thielsen T, et al. "Shock and Go?" extracorporeal cardio-pulmonary resuscitation in the golden-hour of ROSC. Catheter Cardiovasc Interv. 2016;88:691-6.

7. Peigh G, Cavarocchi N, Hirose H. Saving life and brain with extracorporeal cardiopulmonary resuscitation: a single-center analysis of in-hospital cardiac arrests. J Thorac Cardiovasc Surg. 2015;150:1344-9.

8. Wu X, Drabek T, Tisherman SA, Henchir J, Stezoski SW, Culver S, et al. Emergency preservation and resuscitation with profound hypothermia, oxygen, and glucose allows reliable neurological recovery after $3 \mathrm{~h}$ of cardiac arrest from rapid exsanguination in dogs. J Cereb Blood Flow Metab. 2008;28: 302-11.

9. Buckberg GD. Controlled reperfusion after ischemia may be the unifying recovery denominator. J Thorac Cardiovasc Surg. 2010;140:12-8. 18.e1-2.

10. Athanasuleas CL, Buckberg GD, Allen BS, Beyersdorf F, Kirsh MM. Sudden cardiac death: directing the scope of resuscitation towards the heart and brain. Resuscitation. 2006;70:44-51

11. Tisherman SA, Safar P, Radovsky A, Peitzman A, Sterz F, Kuboyama K Therapeutic deep hypothermic circulatory arrest in dogs: a resuscitation modality for hemorrhagic shock with 'irreparable' injury. J Trauma. 1990;30: 836-47.

12. Behringer W, Prueckner S, Safar P, Radovsky A, Kentner R, Stezoski SW, et al Rapid induction of mild cerebral hypothermia by cold aortic flush achieves normal recovery in a dog outcome model with 20-minute exsanguination cardiac arrest. Acad Emerg Med. 2000;7:1341-8.

13. Janata A, Holzer M, Bayegan K, Frossard M, Sterz F, Losert UM, et al. Rapid induction of cerebral hypothermia by aortic flush during normovolemic cardiac arrest in pigs. Crit Care Med. 2006;34:1769-74.

14. Janata A, Weihs W, Schratter A, Bayegan K, Holzer M, Frossard M, et al. Cold aortic flush and chest compressions enable good neurologic outcome after 15 mins of ventricular fibrillation in cardiac arrest in pigs. Crit Care Med. 2010; 38:1637-43

15. Weihs W, Krizanac D, Sterz F, Sipos W, Högler S, Janata A, et al. Outcome after resuscitation using controlled rapid extracorporeal cooling to a brain temperature of 30 degrees $\mathrm{C}, 24$ degrees $\mathrm{C}$ and 18 degrees $\mathrm{C}$ during cardiac arrest in pigs. Resuscitation. 2010;81:242-7.

16. Janata A, Bayegan K, Weihs W, Schratter A, Holzer M, Frossard M, et al. Emergency preservation and resuscitation improve survival after 15 minutes of normovolemic cardiac arrest in pigs. Crit Care Med. 2007;35:2785-91.

17. Janata A, Bayegan K, Sterz F, Weihs W, Holzer M, Sipos W, et al. Limits of conventional therapies after prolonged normovolemic cardiac arrest in swine. Resus citation. 2008;79:133-8.

18. Kilkenny C, Browne WJ, Cuthill IC, Emerson M, Altman DG. Improving bioscience research reporting: the ARRIVE guidelines for reporting animal research. PLoS Biol. 2010;8:e1000412.
19. Weihs W, Krizanac D, Sterz F, Hlavin G, Janata A, Sipos W, et al. Rapid induc tion of hypothermia with a small volume aortic flush during cardiac arrest in pigs. Am J Emerg Med. 2012;30:643-50.

20. Woods RJ, Prueckner S, Safar P, Radovsky A, Takasu A, Stezoski SW, et al Hypothermic aortic arch flush for preservation during exsanguination cardiac ar rest of 15 minutes in dogs. J Trauma. 1999;47:1028-36.

21. Behringer W, Prueckner S, Kentner R, Tisherman SA, Radovsky A, Clark R, et al Rapid hypothermic aortic flush can achieve survival without brain damage after 30 minutes cardiac arrest in dogs. Anesthesiology. 2000;93:1491-9.

22. Behringer W, Safar P, Wu X, Kentner R, Radovsky A, Kochanek PM, et al. Survival without brain damage after clinical death of 60-120 mins in dogs using suspended animation by profound hypothermia. Crit Care Med. 2003;31:1523-31.

23. Wu X. Induction of profound hypothermia for emergency preservation and resuscitation allows intact survival after cardiac arrest resulting from prolonged lethal hemorrhage and trauma in dogs. Circulation. 2006;113:1974-82.

24. Wallmuller C, Sterz F, Testori C, Schober A, Stratil P, Hörburger D, et al. Emergency cardio-pulmonary bypass in cardiac arrest: seventeen years of experience. Resuscitation. 2013;84:326-30.

25. Rock KL, Latz E, Ontiveros F, Kono H. The sterile inflammatory response. Annu Rev Immunol. 2010;28:321-42.

26. Schmidt M, Bailey M, Kelly J, Hodgson C, Cooper DJ, Scheinkestel C, et al. Impact of fluid balance on outcome of adult patients treated with extracorporeal membrane oxygenation. Intensive Care Med. 2014;40:1256-66.

27. Anselmi A, Flecher E. Extracorporeal cardiopulmonary resuscitation for out-ofhospital refractory cardiac arrest: a word of caution. J Thorac Cardiovasc Surg. 2016;151:1217-8.

28. Hamada SR, Delhaye N, Kerever S, Harrois A, Duranteau J. Integrating eFAST in the initial management of stable trauma patients: the end of plain film radiography. Ann Intensive Care. 2016;6:62

29. Cebicci H, Salt O, Gurbuz S, Koyuncu S, Bol O. Benefit of cardiac sonography for estimating the early term survival of the cardiopulmonary arrest patients. Hip pokratia. 2014;18:125-9.

30. Vase H, Christensen S, Christiansen A, Therkelsen CJ, Christiansen EH, Eiskjær H, et al. The Impella CP device for acute mechanical circulatory support in refractory cardiac arrest. Resuscitation. 2017;112:70-4.

31. Ouweneel DM, Schotborgh JV, Limpens J, Sjauw KD, Engström AE, Lagrand WK, et al. Extracorporeal life support during cardiac arrest and cardiogenic shock: a systematic review and meta-analysis. Intensive Care Med. 2016;42:1922-34.

Key Words: resuscitation, cardiac arrest, ECLS, extracorporeal life support, eCPR, EPR, preservation, target temperature management, hypothermia 